\title{
Co-designing personalised nutrition advice with adults aged 65+ years: a user study of the eNutri web app
}

\author{
E. Kelly ${ }^{1}$, M. Weech ${ }^{1}$, R. Fallaize ${ }^{1,2}$, R. Zenun Franco ${ }^{3}$, F. Hwang ${ }^{4}$ and J.A. Lovegrove ${ }^{1}$ \\ ${ }^{1}$ Hugh Sinclair Unit of Human Nutrition, University of Reading, Reading, UK, \\ ${ }^{2}$ School of Life and Medical Science, University of Hertfordshire, College Lane, Hatfield, UK, \\ ${ }^{3}$ Globalyze, Bauru, SP, Brazil and \\ ${ }^{4}$ Biomedical Engineering Section, School of Biological Sciences, University of Reading, Whiteknights, Reading, UK
}

eNutri is an online app that assesses diet with a food frequency questionnaire (FFQ) and provides automated personalised nutrition $(\mathrm{PN})$ advice combined with a diet quality score ${ }^{(1)}$. Evidence suggests PN dietary advice is more effective at improving dietary behaviour than general guidance ${ }^{(1)}$. Previous studies have tested eNutri in UK adults, but it required redevelopment for the older population (65+ years), an age group where nutritional risk is of concern.

Fifteen healthy adults aged $65+$ years were recruited from University volunteer databases. Participants were interviewed via Microsoft Teams about how important a healthy diet is to them, factors that influence their food and drink choices and what they would expect to receive in PN advice before being shown their PN advice from eNutri ${ }^{(1)}$.

Of the 15 participants, $47 \%(n=7)$ were female and the mean age was 73.7 years $(S D \pm 6.3$, range $=67-87)$. Overall, healthy diets were perceived as very important (mean rating $=9.4 / 10$, range $=8-10$ ). The top three factors which influenced participants' food and drink choices were health $(87 \%)$, pleasure/taste $(73 \%)$ and cost $(60 \%)$. For encouraging participants to make changes to their diet, the top three factors selected to be most motivating were general health and well-being $(60 \%)$, losing/maintaining weight $(47 \%)$, and heart health (47\%); $67 \%$ wanted their PN advice tailored to these goals. The three least motivating factors selected by participants were keeping up with others $(67 \%)$, losing/maintaining weight $(42 \%)$, body confidence $(25 \%)$ and improved mood $(25 \%)$. When asked about their expectations of 'personalised dietary advice', $67 \%$ expected to be told which areas of their diet require improvement, $33 \%$ expected to learn why these dietary changes would be beneficial, and $27 \%$ expected details of their nutrient intake. $80 \%$ of those asked $(n=8 / 10)$ also wanted PN advice to show how their BMI and physical activity levels compare against the recommended guidelines.

These results showed that participants would like to identify their personal motivations for changing their diet and receive PN advice tailored to these goals. By doing so, this could increase behavioural control, a key construct in the Theory of Planned Behaviour, which is an important factor in influencing dietary behaviour change ${ }^{(2)}$. Apps have great potential to improve the dietary behaviour of the user ${ }^{(3)}$ and so further research should be conducted with a larger sample size and a more representative sample. Finally, co-design approaches can offer important insights about how to design PN systems to meet the needs of end users.

\section{Acknowledgements}

Food Nutrition Security Cloud (FNS-Cloud) has received funding from the European Union's Horizon 2020 Research and Innovation programme (H2020-EU.3.2.2.3. - A sustainable and competitive agri-food industry) under Grant Agreement No. 863059 - www.fns-cloud.eu. We thank the study volunteers.

\section{References}

1. Fallaize R, Weech M, Zenun Franco R et al. (2020) Agro Food Industry Hi-Tech 31

2. Scannell N, Villani A, Mantzioris, E et al. (2020) Int J Environ Res Public Health 17.

3. Paramastri R, Pratama S, Ho D et al. (2020) Comput Methods Programs Biomed 192. 